\title{
Thoughts on Issues Related to Several Opinions of the General Office of the State Council on Deepening Integration of Industry into Education
}

\author{
Mingrong Du${ }^{1, *}$, Rui $\mathrm{Li}^{2}$ \\ ${ }^{1}$ Department of East Asian Studies, University of Sheffield, Sheffield, CO S2 4QP, UK \\ ${ }^{2}$ Department of International Relations, Huaqiao University, Xiamen, Fujian, co 361021, China \\ ${ }^{*}$ Corresponding author: Mingrong Du (Email: DM2020666@163.com)
}

\begin{abstract}
The Opinions of the General Office of the State Council on Deepening the Integration of Industry and Education (hereinafter referred to as the Opinions) reaffirms some of the educational systems and principles that have evolved in recent years in the field of higher education and vocational education in China, and is also of great significance in cracking the dilemma of vocational education development. The introduction of the Opinions has brought vocational education in China into a new phase, and the policies for the integration of industry and education are gradually being optimised. The current policy of integration of industry and education has a successful practice, on the other hand, also the development of integration of industry and education still faces many bottlenecks and constraints, this paper will take this as a starting point for analysis and reflection.
\end{abstract}

Keywords: Integration of industry and education, China, Vocational Education, Reform, Policy.

\section{Introduction}

The strategy of integrating industry into education is exceedingly paramount to the reform of vocational education, the enhancement of enterprises' competitiveness, and the realisation of a series of national development strategies. Since the reform and opening up, vocational education has been in a role that promotes China's economic and social development both in talent and intelligence. Several Opinions of the General Office of the State Council on Deepening Integration of Industry into Education (hereinafter referred to as Opinions) reaffirms some education systems and educational principles, and the gradual development of higher education and vocational education in China in recent years, which is vital to break the dilemma of the development of vocational education (State Council, 2017a). This article will take the Opinions as a starting point and combine government documents and academic literature to discuss and reflect on the following. This article will firstly analyse the situation of the development of vocational education in China. Secondly, it will discuss the key strategies for the integration of industry into education and analyse whether the policy can further improve vocational education in China. The final part of this paper will summarise the above and make tentative conclusions. The main body of the paper will be addressed separately through tthree-question sections.

\section{What Are the Success and Continuing Challenges to Developing Vocational Education in China?}

Since the beginning of the new century, China has made great developments in vocational education. In reviewing China's development of vocational education, the policy to integrate industry into education has played a key role. China has explored successful experiences in the advancement of vocational education with Chinese elements. Firstly, the attention of the Party and government can serve as a catalyst for the progress of vocational education. Secondly, social demand is the driving force for the vitality of vocational education. Thirdly, economic development has a driving effect on the progress the vocational education system. Lastly, The rise of education quality is the intrinsic motivation of vocational education development. For example, China's vocational schools combine industry with teaching closely, and establish relevant industries according to the majors set by the schools. Promoting mutual support between vocational teaching and enterprise industry. Vocational schools and enterprises are integrated. with each other, combining talent training, scientific research and scientific and technological services. The practice of vocational education in China is organically integrated with the practice of socialist modernisation, constantly innovating theories and systems, facilitating the progress of vocational education, also blazing a path for Chinese-style vocational education that meets international norms.

The crux of integration of industry into education and school-enterprise integration is at the heart of China's development in vocational education. To a great degree, China's vocational education development is still mainly at the school-driven level (Wei et al., 2021). Vocational education also needs to face obstacles brought about by historical inertia, and vocational education at this stage needs to overcome these obstacles, establish new traditions and break through old institutional mechanisms to change the inherent inertia (Chen, 2019). In addition, the challenges facing the vocational education system are more obvious, and in many places there is the problem of unstable vocational education chassis due to the generalisation of secondary education (Guo, 2018).

In addition, according to the State Council (2017b), the development of the integration of industry and education is still facing many bottlenecks and constraints. For example, there is a problem of "two skins" between education talent training and industrial demand, which can mainly be seen in the followings. At the macro level, the integration and benign 
interaction pattern between education and industry has not yet been fundamentally established. The structural conflicts between talents supply and demand has been highlighted. At the micro level, the school-enterprise talent training model collaboration and education in practical has also not yet been formed fundamentally, and school-enterprise cooperation is "hot in schools but cold in enterprises", which is shallow, spontaneous, loose and low-level. Enterprises are not highly motivated to participate in running schools, and there is a relative disconnect between course material and standards of practice, as well as between the teaching and manufacturing process, with the problem of "emphasizing theory over practice" prevailing. At the policy level, there is a lack of holistic and systematic policy supply to encourage the integration of industry into education and school-business collaboration, and the incentive and guarantee services are not yet in place, and the development pattern of government, enterprises, schools, industry and society taking their respective responsibilities and working together is not yet sound.

As for the industries that integrated into education, according to the policy showed in Circular of the State Council on the Issuance of the National Vocational Education Reform Implementation Plan, (State Council, 2019), vocational schools will mainly train high quality technical and skilled personnel to serve regional development, and the corresponding talent training policy will mainly integrate industries serving regional development into education (State Council, 2019). Numerous high vocational schools and main majors that guide reform, assist development, are with Chinese characteristics and are of a world standard will be built in preschool education, nursing, elderly services, health services and modern service industries. China will launcha plan to develop high-level vocational schools and specialisations with Chinese influences, and introduce a number of relevant industries that lead reform, support development and have Chinese characteristics.

\section{What Are Key Strategies to Better Integrate Industries Into Education According to the Policy?}

The core of the integration of industry into education is to make industry enterprises an important subject of schooling (Wei et al., 2021). The national conference on vocational education held in April 2021 specifically states that stateowned enterprises should be used as the lead in promoting the integration of industry and education. Art. 13 of the Opinions states that "backbone enterprises should play a leading role" and that "emphasis should be placed on the role of stateowned enterprises, especially central enterprises, in taking the lead and supporting the participation of various types of enterprises in school-enterprise cooperation in accordance with the law. In conjunction with promoting the reform of state-owned enterprises, support state-owned enterprises with conditions to continue to run and strengthen vocational schools" (State Council, 2017a). As can be seen, strengthening the main position of enterprises and breaking through the bottleneck as a result of the merger of education and industry, which is a key strategy for the integration of education and industry, is also a major initiative to deepen the structural reform of the supply side of education, including both the macroscopic structure and layout of education as well as the reform of the talent training model, as well as the diversification of the organizational form of education and the supply of services, and is an institutional innovation to improve the modern school running system and the education governance system (Xue and Li, 2021). The Opinions clearly propose to "strengthen the main role of enterprises", and in the Guiding Ideas, it is proposed that the construction of the structure of integration of industry into education needs is the key, to "give full play to the vital major role of enterprises" (State Council, 2017a).

In the "Principles", It is advocated that "enterprises completely harness their excitement and initiative to participate in the merger of education and industry.", and build a long-term structure for school-business collaboration", and in the "Main Objectives", it is proposed that" gradually enhance the level of participation of industry and enterprise in school administration" (State Council, 2017a), which can be said to grasp the key of the integration of industry into education to cultivate talents (Guo, 2018). The Opinions adhere to the problem-oriented, focusing on vocational education and higher education directly connected with the job market, enterprise demand, innovation and entrepreneurship, focusing on mobilizing the enthusiasm of enterprise participation, playing an important main role of enterprises, forming a working pattern of government enterprise school industry and society collaborative participation, and focusing on building a package policy system for the integration of industry into education. At the macro level, the government will play a coordinating role, synchronise the planning of integrating education and industry with economic and social development, optimise the layout and structure of vocational and higher education, and promote the linkage between education and industry (Xue and $\mathrm{Li}, 2021)$. At the micro level, it will promote the supply and demand of talents, guide the integration of industrial needs into the supply of talents, promote the integration of supply and demand between industry and education, and support the collaboration between schools and enterprises in the training of talents and scientific and technological innovation (State Council, 2017b). Policy-wise, focus on improving the system, using a combination of investment, taxation, land use, finance and piloting to create incentives to guarantee synergistic support and strengthen organisation and implementation.

In addition, Local government policy innovation to enhance industry-education integration is a critical component of the effective implementation of national policy on industry-education integration. and is crucial to the implementation effect of China's policy on the integration of industry and education. A systematic analysis of the innovation of local governments' policies It is important to the success of China's industry-education integration plan; in the future, the degree of innovation of local governments' policies on integration of industry and education should be further improved in terms of fully considering regional characteristics, constructing policy innovation mechanisms and improving policy innovation capacity.

\section{Will the Policy Be Able to Further Improve Vocational Education in China?}

It is far beyond dispute that the introduction of the policy on the integration of industry into education has brought China's vocational education into a new phase, but whether it can bring sustainable momentum to the development of 
vocational education in China remains a controversial and debatable topic. On one hand, the policy could, to a certain extent, further improve China's vocational education. Since the introduction of Opinions, policy has led to changes in the production plans of various enterprises, which have led to new developments in the development of talent training models in vocational schools. The Opinions were introduced to address the problem of the supply side of talent training not matching the demand side of industrial transformation and upgrading. It facilitates the provision of industry into school, as well as the harmonious development of the students. of education supply and industry demand, the perfection of demand-oriented talent training model, and the basic formation of a positive interaction between vocational education and higher education to support industrial upgrading and economic development. The policy has led to new thinking about China's vocational education in new era, which is significant in enhancing the plight of China's vocational education development.

On the other hand, the policy is still open to question as to whether it can further improve China's development of vocational education, given that times and society are constantly evolving and changing. Since the introduction of the Opinions, the Chinese government has issued a series of related policy documents, all of which are based on recent developments and plans for the future (Xue and Li, 2021). So the policy is constantly evolving, and it will further improve vocational education in China in time, but it will need to be adjusted with the times to meet the realities of the new period.

\section{Conclusion}

In summary, Education is the foundation of a nation and a strong education makes a strong nation. Active improvement of the education situation is of great importance to the development of vocational education and the integration of industry and education in China. the introduction of the Opinions has brought Chinese vocational education into a new stage, and the policy of integration of industry into education is gradually being optimised. In vocational education, government should adhere to the integration of industry into education, follow the rules, clarify the relationship, establish a linkage mechanism between talent supply and industrial demand, let the market promote the professional chain to deeply connect with the industrial chain, and build a community of interests and development. Government should insist on deepening the integration of industry into education, constantly optimizing and improving the policy of integration of industry into education, and cultivating more high-quality skilled talents. Of course, China's policy on the integration of education and industry must also be adapted to the characteristics of the times in order to work better. The optimisation of vocational education is also an issue that requires diversified thinking; the formulation of policies is one aspect, but how to urge local governments, enterprises and vocational schools to actively implement them is also an issue that needs attention.

\section{References}

[1] Chen, S. (2019). 'On deepening the integration of industry into education', Journal of Hebei Normal University/Educational Science Edition, 21(3), pp. 12-21.

[2] Guo, J.R. (2018). 'Integration of Industry into Education to Promote the Development of Vocational Education -Interpretation of Several Opinions of the General Office of the State Council on Deepening Integration of Industries into Education', Jiangsu Jiaoyu, 36, pp. 23-27.

[3] "State Council (2017a). Several Opinions of the General Office of the State Council on Deepening Integration of Industries into $\begin{array}{llll}\text { Education", } & 5 & \text { December } & \text { 2017, }\end{array}$ http://www.gov.cn/zhengce/content/201712/19/content_5248564.htm

[4] "State Council (2017b). A senior official of the National Development and Reform Commission answers questions from the press on Several Opinions of the General Office of the State Council on Deepening Integration of Industries into Education", 19 December 2017, http://www.gov.cn/zhengce/201712/19/content_5248610.htm

[5] "State Council (2019). On the Issuance of National Vocational Education Reform Notice on the Implementation Programme State Development", 24 January 2019, http://www.gov.cn/zhengce/content/201902/13/content_5365341.htm?trs=1

[6] Wei, S.Y. et al. (2021). 'Analysis on the key successful factors of industry-education integration under the Diversified schoolrunning pattern -- A case study of vocational education held by state-owned enterprises', Vocational \& Technical Education Forum, 37(8), pp. 68-76.

[7] Xue, E. and Li, J. (2021) 'The Policy Development of Teacher Ethics Development Since Reform and Opening-Up in China', in Xue, E. and Li, J. (ed.) Creating a High-Quality Education Policy System: Insights from China. Singapore: Springer, pp. $1-10$. 